\title{
La educación en la construcción de la idea de ciudadano, 1910-1948*
}

\section{Resumen}

En el presente artículo se estudia la idea de ciudadano y la construcción del Estadonación en Colombia. Asimismo, se desarrolla una lectura crítica del problema de investigación desde la "vía educativa", entendida como una de las estrategias utilizadas en los países latinoamericanos en formación para modelar el ciudadano y contribuir a la producción de la pretendida homogeneidad cultural. Este es un tema de creciente interés en nuestro país, por cuanto se relaciona con la comprensión del proceso de formación de la nación y construcción del Estado y, en particular, por el aporte a la historia de la educación. El trabajo de documentación condujo a identificar y construir un archivo de la investigación, en el que son centrales los manuales escolares y la documentación oficial. De acuerdo con la búsqueda documental se encontraron 40 textos o manuales escolares, de los cuales 19 correspondían a Historia de Colombia, 16 a Instrucción Cívica y 5 a Urbanidad. Los manuales escolares de historia, instrucción cívica, urbanidad y la documentación oficial de la época constituyen materiales históricos que mediante la crítica de fuentes y la interpretación nos ayudan a comprender los proyectos en juego, las aspiraciones de los diferentes grupos de interés y las tensiones que se vivieron, en la medida que expresan los diseños institucionales, las ideas o valores en torno a la formación del ciudadano que requería la nación colombiana y acerca de cómo difundirlos entre los escolares de ese entonces.

Palabras clave: Colombia, educación, ciudadanía, historia, nación.

Referencia para citar este artículo: MUNOZ MONSALVE, Mónica (2015). "La educación en la construcción de la idea de ciudadano, 1910-1948". En Anuario de Historia Regional y de las Fronteras. 20 (2). pp. 183-213.

Mónica Marcela Muñoz Monsalve: Magíster en Historia de la Universidad Nacional de Colombia, sede Medellín. Correo electrónico: monicamarcelam@yahoo.com.

\footnotetext{
*Artículo de reflexión que se enmarca en la Línea de Investigación Cultura politica y sectores subalternos, coordinada por Óscar Almario García, adscrita al Programa Nacional de Investigación Las culturas políticas de la independencia, sus memorias y sus legados: 200 años de ciudadanías, con código Hermes 9714, financiado por la Universidad Nacional de Colombia y dirigido por Óscar Almario García.
} 


\title{
Education in the construction of a citizen's model, 1910-1948
}

\begin{abstract}
This article will approach to the citizen's model and the construction of the Nation-State in Colombia. Likewise, a critical reading of the research problem is developed from the "educational path", understood as one of the strategies used in the developing Latin American countries to create a citizen's model and contribute to the production of the intended cultural homogeneity. This a topic of a growing concern in our country, since it is related to the understanding of the creation process of a nation and the construction of the State, and especially, by the contribution to the history of education in that regard. The documentation task led to identify and create an archive of the research, in which the school handbooks and the official documentation are crucial as well. According to the documentary search, a total of 40 school texts or handbooks were found, out of which 19 were about the History of Colombia, 16 to Civic Instruction and 5 to Good manners. The history, civic instruction and good manners handbooks, and the official documentation of the time comprise the historical materials that, through the criticism of the sources and the interpretation, help us understand the projects at stake, the expectations of the different concerned groups and the tensions experiences, to the extent expressed by the institutional designs, the ideas or values about the education of that citizen that the Colombian nation needed and about how to disseminate them between the students at that time.
\end{abstract}

Keywords: Colombia, education, citizenship, history, nation.

\section{A educação na construção da idéia de cidadão, 1910-1948}

\section{Resumo}

O presente artigo estuda a idéia de cidadão e a construção do Estado - Nação na Colômbia. Igualmente, desenvolve uma leitura critica do problema de pesquisa desde a "via educacional", entendida como uma das estratégias utilizadas nos países da América Latina em formação para modelar o cidadão e contribuir à produção da pretendida homogeneidade cultural. Este é um tema de crescente interesse no nosso país, já que está relacionado à compreensão do processo de formação da nação e construção do Estado, e em particular pelo aporte à história da educação em quanto tal. $O$ trabalho de documentação levou a identificar e construir um arquivo da pesquisa, na que são centrais os manuais escolares e igualmente a documentação oficial. De acordo com a busca documental, encontraram-se um total de 40 textos ou manuais escolares, dos quais 19 correspondiam à História da Colômbia, 16 à Instrução Cívica e 5 a Urbanidade. Os manuais escolares de história, construção cívica e urbanidade, e a documentação oficial da época, constituem materiais históricos que por meio da critica de fontes e a interpretação, ajudam a compreender os projetos em jogo, as aspirações dos diferentes grupos de interesse e as tensões vividas, na medida que expressam os desenhos institucionais, as idéias ou valores em torno à formação desse cidadão que requeria a nação colombiana e sobre como difundi-los entre os escolares desse então.

Palavras-chave: Colômbia, educação, cidadania, história, nação. 


\section{Introducción}

El análisis acerca de la ciudadanía y de la construcción del Estado es fundamental en este proceso de comprensión, ya que constituye el punto de intersección entre la institucionalidad y la observación de múltiples sectores en búsqueda de la identidad nacional. Vale la pena aclarar que esta identidad viene de los procesos de aculturación de la nación colombiana, así como de los procesos políticos y culturales que tuvieron estos sectores. Adicionalmente, resulta muy interesante observar toda esta cuestión en el ámbito educativo, pues desde allí se pretendió civilizar y moldear de manera especial al futuro ciudadano. Sin embargo, el resultado del proceso de construcción de la ciudadanía estuvo realmente supeditado a las estrategias implementadas desde el Estado, la Iglesia, los Partidos Políticos y otros sectores sociales, en medio de un tenso ambiente político.

Efectivamente, la construcción y orientación de la ciudadanía constituyó una preocupación central para los grupos dominantes y condujo a una clara intervención por parte del Estado en la educación, la cual fue utilizada como instrumento para asegurar el éxito de las estrategias diseñadas. De igual manera, la enorme influencia de la Iglesia Católica y los partidos políticos en el sistema educativo contribuyeron a convertirlo en un espacio de disputas crecientes a lo largo de la primera mitad del siglo XX. En consecuencia, tanto liberales como conservadores coincidieron en concebir la educación como una puerta de entrada a una ciudadanía civilizada, medio ideal para transformar las masas en ciudadanos, es decir, una suerte de espacio y tiempo (la Escuela y sus procesos) que preparaban para el futuro ejercicio de la ciudadanía. Ahora bien, en tanto esa ciudadanía estaba en disputa, entre otras razones por los modelos culturales que competían por la definición de la nación, todas estas tensiones sobre la identidad se trasladaron al sistema educativo, a la Escuela y su vida cotidiana.

Con el propósito de aclarar este fenómeno y sus particularidades en Colombia, es necesario considerar algunas de las investigaciones sobre la construcción del Estadonación y así lograr una aproximación a la relación entre Educación y Manuales Escolares. Para ello, se definen dos ejes centrales que permiten abordar esta problemática.

En la historia política hispanoamericana predominan los estudios sobre el Estadonación moderno como unidad de análisis privilegiada, los cuales por lo general suponen que este definió las colectividades nacionales en un proceso más o menos prolongado de tiempo ${ }^{1}$. En este marco referencial predomina también el falso supuesto de que el proyecto de la homogeneidad cultural, pretendido desde la Independencia, finalmente se había alcanzado aunque con ciertas dificultades o sobrevivencias del pasado, tales como algunas minorías étnicas, el atraso cultural y el analfabetismo, entre otras.

\footnotetext{
${ }^{1}$ Wallerstein se ha referido a que el análisis histórico y social en Occidente ha tenido una tradición “estadocéntrica”. WALLERSTEIN, Immanuel (Coord.), Abrir las ciencias sociales. Informe de la Comisión Gulbenkian para la reestructuración de las ciencias sociales, México: Siglo XXI Editores - Centro de Investigaciones Interdisciplinarias en Ciencias y Humanidades, UNAM, 1999.
} 
Con ello se descarta que otra cara de la historia latinoamericana sea la de los fracasos o desencuentros en ese proceso ${ }^{2}$. De modo que el asunto de la construcción del Estadonación pone en debate temas de gran envergadura, entre ellos ciudadanía y educación, donde esta última fue asociada con ideales de civilizar y moralizar, como parte del juego de las exigencias de la homogeneización, las que justamente fueron inspiradas en las ideas de la Ilustración, promovidas por los criollos que lideraron la lucha contra España y primeros constructores del país independiente, y que se prolongaron durante el curso del siglo XIX. Tal como sostiene Cecilia Sánchez, la educación se concibió como el vehículo para modificar una serie de tradiciones premodernas, que mediante diferentes mecanismos y herramientas tuvo como objetivo esencial la nacionalización de la sociedad .

El caso colombiano es especialmente crítico, porque prácticamente agotó el siglo XIX y comienzos del XX tratando de construir el Estado-nación, sumado a esto el país estaba devastado por la última de las guerras civiles y sus altos costos en vidas y en territorio nacional perdido. También es conveniente considerar que para la configuración del Estado nacional se utilizaron distintas vías y se pusieron en acción diferentes dispositivos, entre los cuales la educación ocupó un lugar central, puesto que en ella se pudo materializar de alguna forma el imaginario ciudadano y la idea de pertenencia a la comunidad imaginada: la nación. El problema de la construcción del Estado nacional adquiere así gran trascendencia en el contexto latinoamericano, no obstante, como lo sugiere la historiadora Mónica Quijada, de lo que se trata ahora es de realizar el análisis desde la Nueva Historia Política, que pretende ir más allá de la historia política institucional, partiendo de que es un proceso mucho más complejo, no lineal y lleno de matices, en la medida que en él confluyen culturas, lenguajes, identidades políticas y actores colectivos ${ }^{4}$.

\section{Naciones y nacionalismos}

Partir de un acercamiento a la problemática del ciudadano, la ciudadanía y su relación con la cuestión de las identidades nacionales es una forma de reconocer su complejidad, pero no queremos que en función de ello se pierda el foco del problema de investigación. El surgimiento de las "naciones" está asociado a términos y conceptos

\footnotetext{
${ }^{2}$ El historiador mexicano E. Florescano, basado en la experiencia mexicana, se refiere por eso a que la historia de este proceso implica considerar tres sujetos simultáneos y no uno solo, pero que el siglo XIX es básicamente la historia de sus desencuentros, lo que tuvo consecuencias en el siglo XX. FLORESCANO, Enrique, "Un conflicto de hoy y del futuro: las relaciones entre las Etnias, el Estado y la Nación en México", en LABASTIDA, Julio, DEL CAMPO, Martín y CAMOU, Antonio (Coords.), Globalización y Democracia. México y América Latina, México, Siglo XXI Editores, 2001, pp. 394. FLORESCANO, Enrique, Etnia, Estado y Nación. Ensayo sobre las identidades colectivas en México, México, Taurus, 2003.

${ }^{3}$ SÁNCHEZ, Cecilia, "El surgimiento de los Estados-Nación y las políticas pedagógicas como herramientas de integración social y de control en Iberoamérica en el siglo XIX”, en ROIG, Arturo Andrés (Ed.), El pensamiento social y político iberoamericano del siglo XIX, Madrid, Editorial Trotta, 2000, pp. 109- 126, 111.

${ }^{4}$ QUIJADA, Mónica, "El paradigma de la homogeneidad", en QUIJADA, M., BERNAND, C. y SHNEIDER, A., Homogeneidad y nación. Con un estudio de caso: Argentina, siglos XIX y XX, Madrid, CSIC, 2000, p. 15.
} 
como emancipación nacional y nacionalismo, que entrañan mitos fundacionales e ideologías, lo que implica reconocer un terreno minado por múltiples interpretaciones, verdades construidas intencionalmente y creencias modernas elaboradas durante casi dos siglos ${ }^{5}$.

Desde la perspectiva de Benedict Anderson, se trata de construir una comunidad imaginada, precisamente porque ya no es posible -por razones demográficas, territoriales, de complejidad social- que sus vínculos sigan siendo los de la proximidad o de la comunidad local o los corporativos, por lo tanto hay que crear vínculos imaginarios, simbólicos, culturales: los mitos comunes, la memoria histórica, el territorio heredado y las tradiciones. En un comienzo, la formación del ciudadano no fue una estrategia que se pudiera generalizar, por cuanto los sectores de elite que dirigieron y triunfaron en el proceso de la Independencia temían igualmente a las masas iletradas, por lo cual los desafíos se concentraron en la construcción del Estado-nación.

Los conceptos nación y nacionalismo ocupan un lugar muy importante como objetos de conocimiento de diferentes disciplinas sociales, específicamente de la ciencia política, la historia y la sociología. Cada una de estas los ha configurado como constructos propios, sin que exista un consenso conceptual. Es decir, ambas nociones son polisémicas. Al respecto Joseph Fontana sostiene que: "El primer problema que nos plantea el nacionalismo es que no lo entendemos demasiado, nos cuesta comprender qué es y de qué está hecho"6.

El nacionalismo tiene diversos significados y usos que varían según el interés que tenga cada sociedad o entidad política. Basta con dar una mirada a lo que fue el nacionalismo para los alemanes de inicios del siglo XX y su influencia en la Primera Guerra Mundial; o para los judíos de mediados del mismo siglo, que les llevó a construir su propio Estado; también para los serbios, bosnios, albaneses y kosovares, que han hecho de Los Balcanes un polvorín que se enciende ante cualquier manifestación nacionalista.

En lo que respecta a la construcción de la nación en Latinoamérica argumenta el historiador Óscar Almario:

A partir de una lectura crítica de los anteriores trabajos, R. Barragán (1999), sostiene que es necesario diferenciar entre lo que significa "imaginar una nación" (papel de las elites) y el proceso histórico de su construcción concreta

\footnotetext{
${ }^{5}$ GUERRA, François-Xavier, "La Nación en América Hispánica: El problema de los orígenes", en GAUCHET, Marcel, MANENT, Pierre y RONSAVALLON, Pierre (Dir.), Nación y modernidad. Buenos Aires, Ediciones Nueva Visión, 1997, pp. 97-120, 97. "Estas huellas de los grandes debates políticos del pasado americano, restos de construcciones historiográficas, son préstamos tomados de la problemática nacional de otros continentes, se convirtieron en lugares comunes propicios para todas las ambigüedades y todos los anacronismos".

${ }^{6}$ FONTANA, Joseph, La historia de los hombres, Barcelona, Crítica, 2002, p. 1.
} 
(proceso histórico real). En efecto, al evaluar este segundo nivel se constata que, en términos de experiencia histórica, existe una gran distancia entre los proyectos imaginados y su cristalización social, lo que explica en buena medida el largo y tormentoso trayecto que para construir las naciones han debido recorrer los países de América Latina y lo accidentado del mismo ${ }^{7}$.

El caso colombiano testimonia esta situación, porque en primera instancia se formalizó la organización del Estado, sus instituciones y la Constitución (Constitución de Villa del Rosario de Cúcuta en 1821). Con respecto a la formación de la nación o a enfrentar los problemas de la identidad, primaron los intereses de los grupos de poder que establecieron sus propias versiones del pasado, buscaron fijar en la memoria sus credos religiosos y políticos, y usaron la alfabetización del pueblo como un criterio para otorgar la ciudadanía. Todo ello tuvo su correlato en el contexto escolar, como veremos.

En otras palabras, el problema de fondo radica en lograr diferenciar entre aquello imaginado y lo que pertenece al orden de la realidad social. En este orden de ideas la historiadora Mónica Quijada ha llamado la atención acerca de por qué para los grupos de poder y dirigentes durante el siglo XIX y principios del XX fue necesario escoger o enfatizar en algunas alternativas que creyeron posibles para responder a los retos que significaba edificar la Nación y el Estado, pero sin olvidar que esas alternativas se inscribían dentro del paradigma dominante de la homogeneidad cultural. En otros términos, aunque hubo un paradigma común o modelo cultural dominante para definir las naciones, también se presentaron matices en ese proceso, como consecuencia de los énfasis o alternativas escogidas en cada caso. Es lo que Quijada llama las vías de la homogeneidad o estrategias que buscaron superar la heterogeneidad social, cultural y étnica, entre ellas: la participación política expresada en el sistema representativo y su principal ritual, las elecciones; y la expansión de la educación, entendida en sus tres ejes complementarios, la alfabetización, la transmisión de la lengua y la configuración de una memoria común, esta última fue una estrategia clave por cuanto permitía articular el conocimiento y la autoridad de las letras, la exaltación de la lengua compartida y el cultivo de una memoria colectiva, requisitos fundamentales en los procesos de construcción de las identidades nacionales ${ }^{8}$.

La dinámica de formar una identidad nacional es inseparable de la construcción de un Estado moderno, esto supone instituir un nuevo sujeto político, el ciudadano, que surge de la transformación de los antiguos "vasallos" en un nuevo sujeto soberano, colectivamente visto como la Nación. También son útiles aquí los argumentos expuestos por Benedict Anderson (y sus comunidades imaginadas), que respaldan sus afirmaciones con relación a la "construcción de la homogeneidad" y cómo en ese proceso la nación se corporiza en el imaginario colectivo, por lo cual sostiene que la nación: "es imaginada porque aún los miembros de la nación más pequeña no conocerán jamás a la mayoría de sus compatriotas, no los verán y oirán siquiera hablar

${ }^{7}$ ALMARIO, Óscar, Los sujetos colectivos en la formación del Estado nacional colombiano, Medellín, Universidad Nacional de Colombia, 2007, p. 18.

${ }^{8}$ QUIJADA, Mónica, “El paradigma de...," Op. cit., p. 19. 
de ellos, pero en la mente de cada uno vive la imagen de su comunión"9. Cabe hacer mención de los planteamientos de Anthony $\mathrm{Smith}^{10}$, quien establece la posibilidad de un solapamiento entre dos modelos de nación, uno llamado "nación cívica" y otro que recibe el nombre de "nación étnica o genealógica". El primero se refiere a las leyes, los derechos, el sistema de soberanía popular y representación colectiva; mientras que el segundo alude a un sistema de cohesión colectiva, fundamentado en referentes comunes, con una connotación de esencialidad que los articula y configura. El modelo de nación cívica está centrado en el Estado y se fundamenta en el ciudadano con derechos idénticos a todos los demás. En cambio, la nación étnica aboga por un sentimiento nacional. Uno y otro se hallan presentes en la construcción nacional.

La estrecha relación entre los anteriores modelos y el propuesto por Mónica Quijada ayudan a matizar la teoría de la nación, específicamente a lo que se ha denominado la “construcción nacional". Esto implica que alcanzar una nación de ciudadanos supone reconocer la presencia en tensión, tanto desde la perspectiva étnica como de la cívica, que finalmente acaban resolviéndose desde el plano del imaginario colectivo. En América Latina el proceso de homogeneización ${ }^{11}$ fue mucho más complejo debido a la heterogeneidad y amplia diversidad étnica, social y cultural, pues implicaba unificar diferentes universos simbólicos en uno solo. La historiadora argumenta que el problema de la nación en Latinoamérica parte de la interacción o tensión entre dos conceptos, la homogeneización y la diversidad. El primero se refiere a los elementos compartidos que hacen que un individuo se reconozca como parte de un grupo y el segundo implica el "auto-reconocimiento y reconocimiento de un grupo en contraposición a otros" $" 12$.

Quijada ${ }^{13}$ parte de reconocer el significativo aporte de $\operatorname{Smith}^{14}$ a la conceptualización de estos problemas, por dos razones sustantivas. La primera alude a que la experiencia de la construcción del Estado nacional en Occidente permite discernir que existen

\footnotetext{
9 ANDERSON, Benedict, Comunidades Imaginadas: Reflexiones sobre el origen y la difusión del nacionalismo, México, Fondo de Cultura Económica, 1991. p. 23.

${ }^{10}$ SMITH, Anthony, Nacionalismo: teoría, ideología, historia, Alianza Editorial, 2007. p. 39. "La nación cívica, dice Smith, se sustenta en un sistema único de ocupación territorial, de poder y de producción, en leyes comunes con derechos y deberes legales idénticos para toda la población, un sistema educacional público y masivo y una ideología cívica. El modelo de nación étnica o genealógica, por su parte, reclama una ascendencia común, mitos de origen, identidad de costumbres y de memoria histórica, y una lengua común".

${ }^{11}$ QUIJADA, Mónica, "El paradigma de la homogeneidad...", Op. cit., p. 8. "Entiende por homogeneidad la tendencia histórica y procesual a eliminar o ignorar las diferencias culturales, étnicas, fenotípicas, etc., de un grupo humano, de forma tal que el mismo sea percibido y se auto perciba como partícipe de una unidad etno-cultural y referencial".

${ }^{12}$ Ibid., p. 15.

${ }^{13}$ QUIJADA, Mónica, "Los confines del pueblo soberano. Territorio y diversidad en la Argentina del siglo XIX”, en COLOM GONZÁLEZ, Francisco (Ed.), Relatos de Nación. La construcción de las identidades nacionales en el mundo hispánico. Madrid / Frankfurt am Mein: Iberoamericana / Vervuert. Vol. II. 2005, pp.821-848, 822 .

${ }^{14}$ SMITH, Anthony D. The Ethnic Origins of Nations, Oxford, Blackwell, 1986; SMITH, Anthony D. La identidad nacional, Madrid: Trama editorial, 1997.
} 
simultáneamente dos grandes modelos y no uno solo como pretende analizarlo la perspectiva modernista (E. Gellner, E. Hobsbawm, B. Anderson). Por lo cual hay que distinguir entre un modelo de nación cívica (sistema único de ocupación territorial y de producción, leyes comunes para toda la población, sistema educacional público masivo y una única ideología cívica) y el modelo de nación étnica o genealógica (ascendencia común, mitos de origen, identidad de costumbres y de memoria histórica y una lengua vernácula). Esta distinción de los dos modelos occidentales en la construcción del Estado-nación explica también la orientación de los dos libros de Anthony Smith reseñados antes, el primero se ocupa de los antecedentes premodernos de las naciones modernas y el segundo de los desafíos prácticos que enfrentan las naciones modernas. La segunda cuestión importante que subraya Quijada de la perspectiva de Smith es la trascendencia de su idea del solapamiento o superposición de las dinámicas de ambos modelos, es decir, que ambos "operan conjuntamente". A partir de este punto y teniendo como referencia la experiencia de situaciones como la de América Latina, Quijada lleva por su propia cuenta, los supuestos de Smith hasta sus últimas consecuencias:

\begin{abstract}
Hasta aquí llega Smith, pero si extraemos las consecuencias - quizá no deseadasde su pensamiento, podemos deducir que la construcción política, institucional, simbólica y, en resumidas cuentas, cívica que entraña el primer modelo, añora y persigue la potencialidad de cohesión que ofrece el segundo modelo -la nación étnica o genealógica- con su capacidad de articular y resignificar las herencias y los préstamos, las recreaciones y las nuevas creaciones ${ }^{15}$.
\end{abstract}

A partir de esta conclusión o sugerencia de Mónica Quijada, se pueden establecer puentes con la perspectiva de este trabajo, como lo intentaremos mostrar en lo sucesivo. Precisamente, la construcción nacional en Hispanoamérica tuvo sus inicios con la crisis de soberanía de la Monarquía hispánica, la vacatioregis y la cuestión de la reasunción de la soberanía por los pueblos, dinámicas que se intentaron canalizar en las Cortes de Cádiz, bajo el ideal de un imperio reformado sobre una redefinición de la nación española y unas bases constitucionales. Desde entonces trató de instaurarse el proyecto de nación y Estado en estas sociedades, donde se alzó la bandera del ciudadano y sus derechos, con un soporte sustancialmente constitucional. Una de las herencias de la Revolución Francesa para los nuevos Estados hispanoamericanos fue el modelo de nación cívica ${ }^{16}$.

La aplicación de un modelo cívico de nación buscó homogeneizar a la población y crear una comunidad política basada en elementos comunes, como las instituciones, los deberes, los derechos y una cultura cívica compartida. Dentro del proceso de modernización, la homogeneidad puede entenderse solo si se analizan sus asociaciones con conceptos claves como nación, nacionalismo y ciudadanía. En otras palabras, es posible comprender la homogenización como una construcción social de interacción entre el contexto y los efectos relacionados con la formación de la

\footnotetext{
${ }^{15}$ QUIJADA MAURIÑO, Mónica, "Los confines del pueblo soberano. Territorio y diversidad en la Argentina del siglo XIX...", Op. cit., pp.821-822.

${ }^{16}$ SMITH, Anthony, The ethnic..., Op. cit., p. 39.
} 
nación, anteriormente mencionados. Este modelo homogeneizador, en Colombia, difundió un ideal de "blanqueamiento ideológico", que efectivamente fue usado para excluir, olvidar y silenciar aquellos grupos de la población que eran rechazados o menospreciados por la visión del proyecto republicano. Esta construcción intentó superar la heterogeneidad y producir la ficción de un colectivo cohesionado, lo que conllevó inevitablemente a la exclusión de unos por otros, el resultado fue un modelo social que, constituido por la supuesta nación de ciudadanos, los hizo partícipes de un mismo universo simbólico orientado hacia el progreso, tal como se puede observar en el Manual de Civismo de Bohórquez Casallas, quién argumenta que:

El pueblo, la sociedad y la familia forman la nación, pero no de cualquier manera. Se requieren ciertos vínculos comunes que determinan una verdadera unidad, cohesión y permanencia. Esta unidad la forma la misma historia, la misma raza, la misma religión y la comunidad de necesidades, intereses y aspiraciones $^{17}$.

Ello adicionalmente se reforzaba con las imágenes que ilustraban este tipo de textos, como se puede observar en la ilustración 1:

Ilustración 1. Elementos como la historia, la raza y la religión, buscan determinar la unidad y cohesión de un colectivo imaginario.

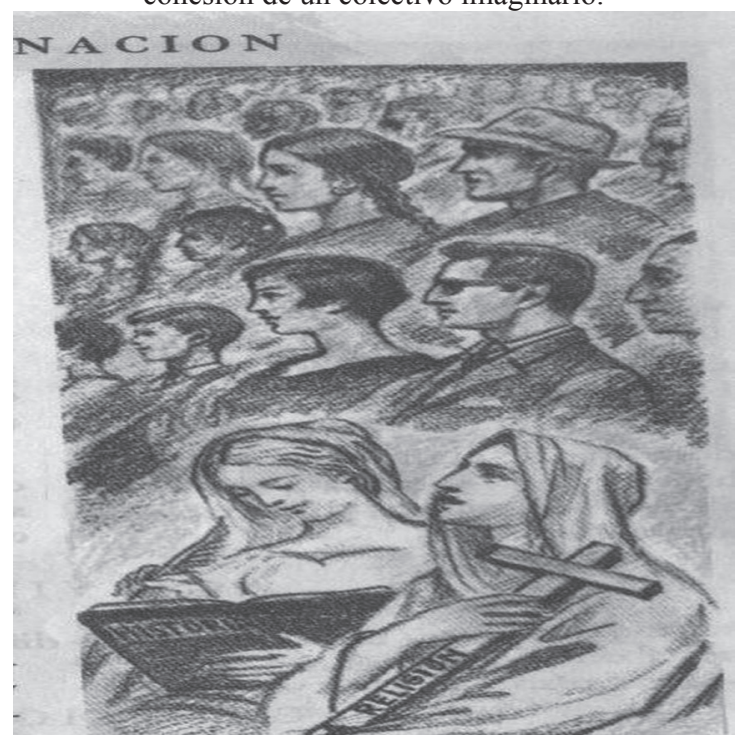

Fuente: Civismo: para el quinto grado de primaria, Bogotá, Voluntad, [s.f.]

Autor: Luis Antonio Bohórquez.

Para Quijada y Guerra es evidente que el proceso de la formación del Estado en Latinoamérica estuvo fuertemente vinculado con el concepto de nación cívica, que mediante prácticas educativas, la lengua común y la memoria histórica compartida,

17 BOHÓRQUEZ CASALLAS, Luis Antonio, Civismo: para el quinto grado de primaria, Bogotá, Voluntad, [s.f.], p.27. 
terminaron conformando la nación de ciudadanos. Esto se puede constatar en la literatura historiográfica, donde los criollos establecieron la libertad e igualdad como una característica relevante de los nuevos Estados frente al antiguo régimen colonial, pues buscaban trazar un camino viable hacia la integración de la nación. Sin embargo, en dicha integración debían incluirse las minorías étnicas, sin decir con ello que se adoptarían las tradiciones indígenas. Según Hans Joachim König:

[...] de manera análoga, la idea de libertad política influyó en la decisión de los grupos dirigentes, en cuanto a que los derechos del ciudadano debían constituir el principal criterio de la afiliación a la nación, que habría de plasmarse dentro de las fronteras de la patria, del país de nacimiento entendido como unidad ${ }^{18}$.

El concepto de nación de ciudadanos se empieza a configurar desde el siglo XVIII, cuando se sustituye la lealtad al monarca absoluto por la lealtad a la nación, con su nuevo pacto político. Para la nación moderna era necesario crear un sentimiento de amor patrio, un sentido de pertenencia abstracto y para ello se recurrió a elementos premodernos o en palabras de Hobsbawm a tradiciones inventadas ${ }^{19}$. Los Estados y las elites crearon mitos, pautas y símbolos, que arraigados en tradiciones, costumbres y creencias, buscaron redefinir, canalizar y generalizar, tejiendo redes de identificación colectiva. Todo esto se articuló al desarrollo de la Instrucción Pública, pues se consideró el escenario indicado para construir los imaginarios ${ }^{20}$ de la acción y el ciudadano. Allí, mediante el uso de los manuales, catecismos y rituales cívicos, se intentaron difundir de manera masiva las ideas de la construcción nacional que tenían los grupos dirigentes. En virtud de esto, en Hispanoamérica el camino hacia la homogeneización de los imaginarios colectivos se trazó primero por medio de la participación política y su trascendental ritual, las elecciones, y luego mediante la expansión de la Educación o Instrucción Pública.

De esta forma, la educación se constituyó en un elemento clave en la gestación de la memoria histórica, en la medida que las construcciones de imaginarios estuvieron cargadas de recuerdos, olvidos, recreaciones y mitificaciones. Ahora bien, la memoria histórica incidió fuertemente en la sociedad y en las acciones de los que estudian y narran la historia, contribuyendo a la formación de una identidad política y a la memoria de una cultura específica. La memoria común fue definitiva en rituales colectivos, mitos, ceremonias y culto a los héroes, al respecto afirma Quijada:

\footnotetext{
${ }^{18}$ KÖNIG, Hans Joachim, (Comp.), Estado-nación, comunidad indigena, industria: tres debates al final del milenio, Asociación de Historiadores Latinoamericanistas Europeos, 2000, p. 39.

${ }^{19}$ HOBSBAWM, Eric y RANGER, Terence, The Invention of Tradition, New York, Cambridge University Press, 1983.

${ }^{20}$ BACZKO, Bronislaw, Los imaginarios sociales. Memorias y esperanzas colectivas, Buenos Aires, Nueva Visión, 1984. p. 8. "[...] lo define como una forma determinada de ordenamiento de un conjunto de representaciones que las sociedades se dan a sí mismas, las cuales tienen una realidad específica que reside en su propia existencia, en su impacto variable sobre las mentalidades y los comportamientos colectivos, en las funciones múltiples que ejercen en la vida social y en su capacidad para influir sobre la toma de decisiones políticas".
} 
Es decir, el historiador convertido en constructor de su nación ofrece a la memoria colectiva un proceso histórico en el que el pasado contiene ya la promesa cierta de un brillante futuro, y en el que la ruptura del orden colonial significa que el país ha asumido de modo irrevocable esa vocación democrática que sin que lo supiera ha sido ya la suya desde los orígenes ${ }^{21}$.

El proceso de la memoria histórica en Hispanoamérica cumplió un papel seleccionador, incluyendo y excluyendo los segmentos del pasado que suscitaban o podían suscitar dislocaciones o conflictos en el imaginario colectivo y obstaculizar la cohesión de la "comunidad imaginada". Además, la memoria histórica interviene, según Quijada, afectando mitos de origen y actuando como espejo de desencuentros del pasado que se proyectan en el presente.

\section{Ciudadanías}

La ciudadanía política moderna, según Pierre Rosanvallon, supone "una ruptura completa con las visiones tradicionales del cuerpo político", pues "la igualdad política marca la entrada definitiva en el mundo de los individuos" 22 . Para Ronsavallon, era necesario borrar la brecha existente entre "el pueblo principio" y "el pueblo sociológico". Desde esta perspectiva -la regeneración del cuerpo político mediante la participación unánime de este en la defensa de la patria-, en la práctica las iniciativas se vieron confrontadas a la distinción tajante entre una "ciudadanía política", ligada a criterios objetivos de capacidad (vecindad, riqueza...) y una "ciudadanía del soldado", integradora y democrática.

Ciertamente, al comienzo de este proceso el poder político estaba en manos de las elites criollas y el ejercicio de los derechos políticos - como el derecho del sufragiose restringía a sectores privilegiados de la población, lo que equivale a decir que evidentemente indios, negros y mestizos continuaban excluidos de la participación política. Posteriormente, en forma gradual, el proceso de ciudadanización significó la ampliación de la base social de la nación en formación. Respecto del sufragio se afirma en el manual de civismo de Bohórquez Casallas que:

El sufragio o voto, es el acto público mediante el cual los ciudadanos ejercen el derecho político de elegir a sus representantes y mandatarios. El sufragio se realiza en las elecciones públicas por medio del voto; constituye no solo el principal derecho democrático, sino un primordial deber cívico de todo ciudadano ${ }^{23}$.

Las recientes interpretaciones acerca del sufragio en la formación de la cultura política buscan transcender la simple práctica de la expansión del voto y su ejercicio, al reconocer que las elecciones se convirtieron en un principio de soberanía popular, que en su representatividad debía realizar la voluntad de la nación, compuesta por

\footnotetext{
${ }^{21}$ QUIJADA, Mónica, "El paradigma de la homogeneidad...”, Op. cit., p 44.

22 ROSANVALlON, Pierre, La consagración del ciudadano: historia del sufragio universal, México, Instituto Mora, 1999, p.14.

${ }^{23}$ BOHÓRQUEZ CASALLAS, Luis Antonio, Civismo..., Op. cit., p. 10.
} 
una comunidad abstracta de individuos, aunque de fondo conformada por grupos diferenciados. A los ciudadanos se les reservaba el derecho a elegir y ser elegidos, pero a través de un proceso complejo en el que se superponían la tradición y la modernidad. En los estudios de Hilda Sábato ${ }^{24}$ se puede observar cómo con frecuencia el concepto de ciudadano se superponía al de vecino, en una mezcla de nuevos y viejos criterios para definir el sujeto de representación. Dicho sujeto de representación fue la preocupación de las elites que asumieron el poder en distintas regiones y países de Iberoamérica, tal como se puede evidenciar en los diferentes cambios de legislación, que respondían a los variados momentos ideológicos y políticos y a la correlación de fuerzas en disputa. A pesar de que las prácticas eleccionarias fueron continuas y en muchos casos fraudulentas, estas no fueron el único camino al poder del Estado, porque como es bien sabido también fue frecuente el camino de las armas o de la fuerza, como modalidades que ampliaban el espacio de las luchas políticas.

En sus investigaciones, Hilda Sábato ${ }^{25}$ también resalta unos rasgos característicos en el panorama latinoamericano, entre los que se destacan: un bajo porcentaje en la participación de los comicios electorales, muy restringido en algunos países. De las personas habilitadas no todas acudían a las urnas, la participación estaba organizada y manipulada por el Estado e incluso por maquinarias políticas; se constituyeron partidos políticos, se implementaron ceremonias y fiestas cívicas que se convirtieron en ingredientes de celebración y rituales colectivos.

En un primer análisis sobre las elecciones en los países hispanoamericanos, se puede encontrar que hablar de democracias representativas era un espacio que estaba reservado para los grupos de poder, de los que hacían parte los criollos descendientes de europeos. No obstante, la población latinoamericana buscó una base electoral más amplia y para ello el voto se difundió de forma paulatina, lo que constituyó un factor de disputas entre los liberales y conservadores. Empero, en la medida en que se ampliaba la base de la ciudadanía, se hacía presente la cuestión étnica. En países como Colombia, la normativa electoral fue bastante restringida, dejando por fuera de los comicios a un significativo número de la población que no cumplía los requisitos establecidos en dicha norma, a diferencia de países como México y Argentina donde diversos sectores sociales formaron parte de la base electoral, lo que permitió que las elecciones sí contribuyeran a la homogeneización de diferentes grupos en una misma cultura política. De tal manera que los gobernantes de las nuevas repúblicas se propusieron expandir y consolidar la educación de las masas populares. De esta forma comenzaron a preocuparse por convertir las masas iletradas en ciudadanos ilustrados, aspecto en el que se concentraría el papel transformador de la educación ${ }^{26}$.

\footnotetext{
${ }^{24}$ SÁBATO, Hilda, (Comp.), Ciudadanía politica y formación de las naciones: perspectivas históricas de América Latina, México, El Colegio de México, 1999.

${ }^{25}$ Ibid. p. 54.

${ }^{26}$ QUIJADA, Mónica, “El paradigma de la homogeneidad...”, Op. cit., p. 22. "Occidentalización y civilización pasaron a ser sinónimos de educación, ya que con las prácticas educativas se buscaba difundir entre los indígenas unas costumbre y un imaginario integrados en el universo simbólico de la sociedad mayoritaria".
} 
Así como el sufragio y el sistema representativo fueron vías para la formación de la homogeneidad en Colombia, la educación fue otra ruta efectiva que se asoció para ello con la lengua, en términos de intervenir de conjunto en la implementación de la castellanización como "lengua nacional" y componente fundamental en la formación de ciudadanos, sirviendo como puente entre la homogeneización y la construcción de la memoria histórica. Al respecto se evidencian notables diferencias con el caso argentino, en donde no se establecieron restricciones censatarias (de propiedad o alfabetización) frente al voto, ni se les retiraron los derechos de la ciudadanía a sectores sociales. Justamente Colombia fue uno de los países del área en donde el ejercicio de la ciudadanía tuvo como condición restricciones en este sentido, las cuales se mantuvieron incluso hasta bien entrado el siglo XX. ${ }^{27}$ Según Quijada: "En muchos puntos de Hispanoamérica fueron surgiendo cláusulas que obligaban al alfabetismo para poder ejercer el derecho al voto, lo que marginaba a amplias capas de la población de las prácticas representativas"28.

De manera que durante buena parte de los siglos XIX y XX operaron al tiempo dos tendencias: una hacia la reivindicación de los derechos individuales, políticos, civiles y de representación política y otra que mediante una escala jerárquica, ubicaba en ciertos rangos a los blancos cultos y los no blancos incultos, considerados estos últimos como "razas inferiores" (indígenas, negros y sus múltiples cruces).

Desde el poder político se emprendieron múltiples iniciativas, dado que para las elites ilustradas y los sectores dirigentes la construcción de la ciudadanía constituía un proyecto central hacia la conformación de las nuevas comunidades políticas. Sin embargo, para ejercer el papel que se les pretendía asignar en el nuevo sistema representativo, la mayor parte de la población iberoamericana no estaba preparada por razones culturales. Por ello, una de las alternativas utilizadas para evitar riesgos fue la restricción de la participación política. En tanto persistía la contradicción de una ciudadanía incompleta, se propuso educar a la población con base en los principios heredados de la Ilustración y redefinidos por la República, así como difundir sus valores y prácticas. Con ese fin, se promovió la creación de instituciones educativas y culturales, se buscó la consolidación de sistemas educativos, asimismo, la promoción del patriotismo y las virtudes cívicas. Por otra parte, formar opinión pública fue considerado uno de los pilares de la legitimidad política, lo que contribuyó a que la prensa y las publicaciones periódicas se posicionaran en amplios sectores de la sociedad. ${ }^{29}$

\footnotetext{
${ }^{27}$ GÓMEZ, Elías, La ciudadanía en el federalismo. El proceso de construcción de ciudadanos en el Estado soberano de Cundinamarca 1863-1878, Bogotá, Editorial Pontificia Universidad Javeriana, 2009. p. 74. Este autor expresa en cuanto al caso colombiano que: "Uno de los aspectos más relevantes en el proceso de construcción de la ciudadanía es la forma en que distintos sectores sociales, acogieron y modificaron, los proyectos estatales encaminados a promoverla o limitarla. Los alcances de la representación política moderna, propuesta desde el Estado, estuvieron condicionados por su implementación en una sociedad influenciada por valores y lazos de solidaridad tradicionales".

${ }^{28}$ QUIJADA, Mónica, "El paradigma de la homogeneidad...”, Op. cit., p.50.

${ }^{29}$ GÓMEZ, Elías, La ciudadanía en el federalismo. El proceso de construcción de ciudadanos en el Estado soberano de Cundinamarca 1863-1878, Bogotá, Editorial Pontificia Universidad Javeriana, 2009.
} 
En efecto, la construcción de ciudadanía hizo parte de un proceso cultural, "El ciudadano no nace, se hace" ${ }^{30}$, así lo sostiene François-Xavier Guerra, emblemático historiador de estos procesos en América Latina. Es preciso entonces señalar que existen profundas diferencias entre el vasallo del antiguo régimen y el ciudadano de las sociedades modernas; para el primero, la nación hace referencia a una alianza entre pueblos, el vasallo como vecino de un pueblo es parte inseparable de un cuerpo político y social, cuya cabeza es el monarca con todo lo que representa (soberanía y majestad); para el segundo, la ciudadanía se entiende como un nuevo vínculo o pacto con una comunidad abstracta que es base de la nueva soberanía; por consiguiente, se espera que el ciudadano moderno exprese otra concepción de la sociedad y la política. En pocas palabras, se trata de un nuevo orden social y político organizado por el Estado, fundamentado en las relaciones entre el ciudadano (sujeto moderno) y la nación (comunidad imaginada), que debe garantizar las libertades de los asociados, en un principio inspirados en el modelo del federalismo estadounidense y de la Revolución Francesa, con el fin de que se marcara una ruptura con el antiguo régimen.

En la cultura política hispánica, el concepto de ciudadano comenzó a tomar forma con la crisis de la monarquía y sus atributos a delinearse desde las Cortes de Cádiz (1810-1814), en donde se caracterizó al ciudadano moderno, otorgándole propiedades como la universalidad y la igualdad jurídica, en contraste con el ciudadano del antiguo régimen monárquico, que se asoció más con el concepto de "vecino"31.

Como señala Guerra, puede entenderse el ciudadano como el vecino de una "ciudad" ideal que goza de sus privilegios consagrados en la ley, como miembro de pleno derecho en una comunidad política. El autor distingue dos fases en la ciudadanía: en primer lugar, se habla del ciudadano premoderno que se define por la pertenencia a un grupo; en segundo lugar, un ciudadano moderno como parte de una colectividad abstracta: la nación o el individuo ${ }^{32}$.

El concepto de ciudadano se vincula estrechamente con la pertenencia a una ciudado nación, incluso esto se puede observar en el sistema eleccionario, donde el sufragio compuesto por prácticas y representaciones específicas es un acto colectivo, en el cual simbólicamente se materializa la reunión de la nación.

Aunque el voto no necesariamente garantice que existe un ciudadano moderno, en las pretensiones del sufragio se encuentra, en buena medida, la idea de legitimar el poder en cabeza de un soberano y crear el imaginario de que en las urnas se reúne la

\footnotetext{
${ }^{30}$ GUERRA, Françoise-Xavier, "El soberano y su reino. Reflexiones sobre la génesis del ciudadano en América Latina”, en SÁBATO, Hilda (Comp.), Ciudadanía política y formación de las naciones. Perspectivas históricas de América Latina, México, El Colegio de México, 1999, pp. 33-181, 33.

${ }^{31}$ Ibid., p. 47. "Siguiendo las ideas del autor en cierta manera la nación moderna es concebida como una vasta ciudad. Por tanto, muchos de los atributos del ciudadano remiten, generalizándolos y abstrayéndolos, a los de vecino. La nacionalidad - pertenencia jurídica a la nación- generaliza el vecinazgo como origen: ser natural de...".

${ }^{32}$ Ibid., p. 42.
} 
voluntad de la nación. A pesar de los intentos por establecer una ruptura radical con el antiguo régimen, lo cierto es que este hereda imaginarios y prácticas a la nación moderna.

La ciudadanía en Latinoamérica tenía, entonces, varios retos para modelar el ciudadano moderno. Para ello era necesario implementar nuevas prácticas políticas, promover cambios culturales y formar partidos políticos, que precisamente reforzaron la idea de un ciudadano nuevo, diferente al del Antiguo Régimen, que Francisco-Xavier Guerra define como una "pedagogía" colectiva ${ }^{33}$.

El título de ciudadano resultó fundamental en los intereses de los grupos dirigentes, para motivar a amplios sectores de la población en torno a los nuevos Estados, vincularlos con valores y cualidades como la igualdad, la participación política, la libertad y el progreso económico, que constituían promesas del nuevo sistema. Bajo el estatus de ciudadanos y con el señuelo de la igualdad, se pretendió incluir a las llamadas "minorías" étnicas, considerándolas como miembros del Estado y otorgándoles derechos que hasta entonces no se les habían concedido. En resumen, con base en la ideología de la "unidad nacional", se buscó que el conjunto de la población se identificara con los nuevos Estados nacionales. Así define al ciudadano en el manual Carlos Alberto Lleras en Instrucción Cívica:

Viene de ciudad -civitas- y llamase así el vecino de ella, por nacimiento, optimo jure, o bien por adquisición superior ulterior de ese título, que importa preciosos derechos. En la antigüedad el título de ciudadano era mucho más estimado que en los tiempos actuales -Civisromanus-ateniensis-y servía por doquiera como salvaguardia o escudo ${ }^{34}$.

Para el caso argentino, la “ciudadanización” se encargó de borrar o eliminar la memoria colectiva del indígena, condenándola a su desaparición, en una estrategia que, si se contrasta con el caso colombiano, muestra algunas coincidencias. En efecto, en el afán por civilizar y homogeneizar a la población se utilizó una educación que, apoyada en los manuales escolares de historia, instrucción cívica y urbanidad, promovió la idea de un ciudadano blanco y de estirpe europea. Es por ello que en la mayoría de manuales escolares desaparece, se invisibiliza o sencillamente se pasa de largo, lo concerniente con los antepasados indígenas.

La "ciudadanización" fue otra vía para la homogeneidad y la cohesión colectiva, donde los estereotipos de raza blanca y cultura europea predominaron en algunos países, así como contribuyó a convertirla en referente identitario en Latinoamérica. Paulatinamente, la figura del ciudadano virtuoso fue sustituida por una nueva conceptualización de ciudadano capaz de civilizarse, en la cual se reconoce un margen de exclusión, identificando y diferenciando a aquellos que no eran aptos para alcanzar

\footnotetext{
${ }^{33}$ Ibid., p. 60. "Hacía falta, igualmente, una pedagogía para crear la nación y difundir la imagen de ciudadano moderno: mediante la escuela, la simbología, las ceremonias, el calendario...".

${ }^{34}$ LLERAS ACOSTA, Carlos Alberto, Instrucción cívica, Bogotá, Talleres del Ministerio de Guerra, 1927, p. 23.
} 
la civilidad. Es aquí donde el discurso de la modernidad tomó formas y fuerzas definitivas, las imágenes del indio y el negro comenzaron a verse como señales de atraso, ignorancia y animadversión. Estos elementos también estuvieron presentes en los manuales escolares y por eso sus textos promovían y exaltaban la formación, los deberes y derechos del perfecto ciudadano, tal como lo enuncia el institutor Camilo Jiménez:

El "Perfecto Ciudadano" está precisamente delineado en las páginas de este libro. Allí aparece este tipo ideal humano de las sociedades, tan difícil de encontrar en la realidad. Pero la aproximación a él, demanda un constante esfuerzo de los seres que conviven sobre un territorio, que hablan una misma lengua y a quienes son comunes una determinada historia de glorias y reveses, de alegrías e infortunios, de tradiciones y leyendas ${ }^{35}$.

En el contexto latinoamericano, tanto la visión de ciudadanía como la de nación han sido estudiadas debido a su indiscutible incidencia en la construcción nacional. A este interés se suman las complejas condiciones en que las nuevas naciones debieron intentar sus respectivos ingresos a la modernidad política. Para encarar este reto, los grupos dirigentes consideraron la educación como una de las vías más efectivas para asegurar el éxito. En concreto, la educación sería la encargada de lograr esta transformación, razón por la cual los distintos gobiernos del siglo XX centraron su atención en ella y trataron -con la participación de diversos actores y nuevos métodos e instituciones- de intervenirla y ejercer un control sobre qué se enseñaba y a quién se enseñaba. En tal sentido, se ocuparon incluso de buscar los mecanismos para inspeccionar la Instrucción Pública. De allí el interés por supervisar las prácticas y funciones de los maestros, directivos y educandos; también de los instrumentos y herramientas del proceso de enseñanza, como los manuales escolares, pues estos serían los encargados de reproducir las ideas de patria, nación, ciudadanía e identidad nacional que circularían en las escuelas y colegios de la República.

Para comprender mejor este asunto es necesario analizar cómo se han conceptualizado estas categorías desde los manuales escolares de historia, instrucción, cívica y urbanidad; cómo fueron utilizados en la Escuela y qué imaginarios o prácticas se institucionalizaron en torno a ellos en el sistema escolar. Justamente en este escenario, los sectores dominantes transmitirían su visión sobre el proyecto nacional, por lo mismo los manuales escolares permiten observar las tensiones en torno al poder, las disputas partidistas, el despliegue de las ideas e imaginarios acerca de la Nación y el Estado y las diferentes propuestas sobre la formación de los niños y jóvenes como futuros ciudadanos.

En conclusión, es evidente que los conceptos de nación, nacionalismo e identidad nacional, así como los imaginarios y dispositivos que los acompañaron (de manera especial los manuales escolares de historia, instrucción cívica y urbanidad), sirvieron para difundir las ideas de los grupos de poder, quienes se aprovecharon de

\footnotetext{
35 JIMÉNEZ, Camilo, Instrucción civica: Segundo grado. Texto para la enseñanza primaria, Bogotá, Librería Stella, 1948, pp. 5-6.
} 
la circulación de los textos y del control de sus versiones autorizadas, para instalarse en el espacio educativo. Obviamente, la estrecha conexión entre la educación y uno de sus principales instrumentos, los manuales escolares, se constituye en un eje central para analizar los avances que en esta materia se desarrollaron en la Colombia de la primera mitad del siglo XX.

\section{La educación y los manuales escolares en Colombia}

El tema de la educación y los manuales escolares ha centrado la atención de estudiosos de diferentes disciplinas, ya que mediante su documentación y análisis se puede dilucidar el papel de la educación en ese período, indagar acerca de la importancia de los manuales escolares en la formación de una comunidad de letras, así como identificar los actores educativos que interactuaron con ellos y los convirtieron en importantes, describir las representaciones colectivas en juego y relacionar todo esto con un momento particular de la formación de la nación colombiana. Efectivamente, en las investigaciones sobre los manuales escolares en Colombia se pueden reconocer importantes avances relacionados con la cuestión de la ciudadanía y la formación de una historia patria ${ }^{36}$. Historiadores, pedagogos y académicos de las Ciencias Sociales se han interesado en ponderar la importancia de dichos documentos y la problemática a la que aluden, para concentrarse especialmente en la función que desempeñaron en la construcción del imaginario nacional.

A partir de una aproximación teórico-metodológica a los estudios de Alarcón Meneses, se puede decir que estos materiales son primordiales a la hora de abordar el problema de la historia de la educación en Colombia, precisamente porque se aplicaron a la cuestión de la formación del sujeto moderno requerido por la República, el ciudadano, proceso que en buena parte se desarrolló en los espacios escolares, donde el imaginario estuvo marcado por los ideales de Dios y Patria.

Vale la pena mencionar que el legado de la Regeneración y el dominio conservador incidieron para que en la instrucción pública se entronizaran elementos ideológicos que, amparados en las leyes de la época, sirvieron para organizar el sistema educativo de acuerdo con principios de la doctrina católica como factor de cohesión de la colectividad. Este modelo conservador y católico en la educación se mantendría hasta 1930, cuando los liberales se hicieron al gobierno nacional e intentaron un modelo de laicización de la vida social, que se acompañó de reformas importantes a nivel educativo y político.

Tales políticas influyeron para que los textos escolares trataran de transmitir las virtudes que debían poseer los nuevos ciudadanos y así pudieran ser considerados dignos de ingresar en la comunidad cívica moderna, en la nueva República. Los autores de dichos manuales eran reiterativos en que los niños y jóvenes de la república respetaran y amaran a la patria, de igual manera debían ser fieles a sus instituciones ${ }^{37}$.

\footnotetext{
${ }^{36}$ Entre los cuales sobresalen los trabajos de Luis Alfonso Alarcón Meneses, Alexis Pinilla y César Augusto Lenis Ballesteros. Dichos textos son referentes obligados en la investigación y se relacionan en la bibliografía utilizada por este trabajo.

37 QUIJADA, Mónica, “¿Qué Nación? Dinámicas y dicotomías de la nación en el imaginario hispanoamericano del siglo XIX”, en Cuadernos de Historia Latinoamericana. No. 2. Hamburg. Asociación
} 
De manera que las que se pueden considerar "Pedagogías cívicas", promocionaron la asimilación política y cultural de elementos claves en la formación del ciudadano en el contexto colombiano, tales como la Patria y Dios, que se situaron en primer orden al lado de nociones como pueblo, ciudadanía, soberanía, que sirvieron al objetivo de construir un ideal republicano. No hay duda de que el tema religioso predominó incluso por encima de la lengua, la geografía y la historia, esto contribuyó a la formación de un imaginario social que encontró en la Escuela un espacio propicio para su divulgación y adoctrinamiento, así mismo, como una suerte de réplica de la función de la Iglesia. Lo anterior explica que en las aulas de clase se realizara una oración al iniciar la jornada académica, que en las paredes estuvieran presentes las imágenes religiosas como el Sagrado Corazón y la Virgen, al igual que los retratos de los padres de la patria Bolívar y Santander.

Estas prácticas se alternaron con otros rituales de carácter cívico, moral, patriótico y religioso, que se consideraban parte del proceso de formación de ciudadanos y tuvieron tanto arraigo en la sociedad colombiana que a pesar de las propuestas laicas emprendidas por los liberales, difícilmente se modificaron o se vieron seriamente afectadas. En este sentido tienen validez los planteamientos de Alarcón Meneses, quien en su texto Católicos y patriotas destaca cómo la formación de buenos católicos conduciría a la formación de buenos ciudadanos.

Asimismo, se puede evidenciar que en los diferentes manuales escolares de historia, instrucción cívica y urbanidad, utilizados en las escuelas durante la primera mitad del siglo XX, esta invocación de lo "divino" o las referencias a la "Providencia" fueron no solo recursos retóricos sino componentes fundamentales del proyecto de nación y ciudadanía, que además tuvieron la facultad de llegar hasta amplios sectores de la población, padres de familia de los escolares, que en su mayoría eran católicos. Para formar el "ciudadano católico" se hizo necesario pensar en la educación del niño que asistiría a las escuelas y que posteriormente se convertiría en la base de la nación, por lo que era necesario instruirlo y enseñarle.

Ahora bien, el término patria tuvo múltiples usos y variantes en los manuales escolares. Alarcón Meneses sostiene que la expresión patria se empleó mucho más que la palabra nación en dichos manuales del siglo XIX, hipótesis que al parecer también se mantendría en las expresiones de los textos escolares del siglo XX. Es decir, a partir de una tradición de identidad territorial, la expresión patria ayuda a formar la nueva comunidad política que se basa en una identidad abstracta e intangible de quienes comparten un territorio y se fundamenta en la soberanía popular, donde precisamente tendería a identificarse con el Estado-nación. Como señala Quijada ${ }^{38}$,

de Historiadores Latinoamericanistas Europeos, 1994, pp. 21-24. Estos argumentos sobre la fidelidad patria se explican porque como parte de la formación de la nación, la patria establece un nexo entre la identidad y el territorio: "durante el cual prevalece un imaginario que reclama lealtad a la patria, o lo que es igual, a la tierra donde se nace y se espera morir".

${ }^{38}$ QUIJADA, Mónica, “¿Qué Nación? Dinámicas...”, Op. cit., p. 24. "En Hispanoamérica, la asociación de la 'patria' a la 'nación' conllevó la selección, reelaboración y construcción de memorias históricas que actuaran, a la vez, como elemento de legitimación de las nuevas unidades políticas, como factor de reafirmación en el presente y augurio venturoso del común destino, y como singularidad capaz de 
el sentido de patria se relaciona con la tradición hispánica en referencia a la tierra natal, al terruño, pues a la tierra se está atado, como soporte físico y simbólico de la existencia cotidiana.

El territorio es, entonces, uno de los elementos diferenciadores entre la nación étnica y la nación cívica. Para esta última, la unidad territorial está sustentada en la comunidad política que reside en un mismo territorio y a la que pertenece el conjunto de la ciudadanía. Visto desde la concepción genealógica, se cimenta sobre una ascendencia común, unos mitos de origen, una memoria histórica, la lengua, la identidad, las costumbres.

Estos planteamientos sobre la patria se pueden observar en los textos escolares, con diferentes modalidades y registros. Por ejemplo, mediante versos, en el texto de Historia de Colombia, de los Hermanos Maristas, la idea de patria se asocia con la "Tierra en que nacimos", nótese que ya no se trata de la patria chica de los territorios directamente conocidos, sino del territorio abstracto de la patria, tan abstracto y desconocido como la nación, pero que se puede hacer querido y próximo por los imaginarios compartidos:

Recitaciones.

Para la izada de la bandera en el colegio.

PATRIA.

Patria es la tierra donde se ha sufrido,

Patria es la tierra donde se ha soñado,

Patria es la tierra donde se ha luchado.

Patria es la tierra donde se ha vencido.

Patria es la selva, es el oscuro nido,

La cruz del cementerio abandonado,

La voz de los clarines que ha rasgado

Con su flecha de bronce nuestro oído.

Patria es la errante barca del marino

Que en el enorme piélago sonoro

Deja una blanca estela en su camino.

Y patria es el airón de la bandera

Que ciñe con relámpagos de oro

El sol, como una virgen cabellera ${ }^{39}$.

Las anteriores consideraciones permiten indicar cómo el amor por su tierra debía identificar al individuo de la nación moderna, hasta convertirse en un devoto de dos amos: Dios y Patria. Así, la patria resulta siendo un término presente en el imaginario del ciudadano a través del discurso educativo ${ }^{40}$.

sobreimponerse a la 'identidad americana'. Sobre todo, que pudieran penetrar con la fuerza del mito una memoria social característicamente heterogénea y articulada en torno a la dialéctica dominador/dominado".

${ }^{39}$ HERMANOS MARISTAS, Aprendamos nuestra historia, Bogotá: Voluntad, 1945, p. 157.

${ }^{40}$ KNIGHT, Alan, "Pueblo, política y nación, siglos XIX y XX”, en Víctor Manuel Uribe y Luis Javier Ortiz Mesa (Eds.), Naciones, gentes y territorio, Medellín, Universidad de Antioquia, pp. 370-406. Por 
En definitiva, los sectores dirigentes se valieron del espacio escolar, de los rituales cívicos de carácter público y de una memoria compartida en las historias patrias, para formar ciudadanos. En este punto cabe destacar los aportes de César Lenis, quien sostiene que la memoria histórica difundida por medio de la educación pretendió consolidar proyectos identitarios en Colombia ${ }^{41}$. Agrega Lenis que es justamente por las disputas en torno a la identidad, que los manuales escolares son muy valiosos como fuentes para explorar diferentes problemas de largo alcance en el proceso de formación de la nación colombiana; en tal sentido sustenta que:

Precisamente, la memoria colectiva, a aquellos que la cultivan y la conservan, sirve para proveerlos de referentes del pasado que los identifiquen. Experiencias vividas, selección de acontecimientos, difusión de figuras representativas, características del grupo humano, entre otros aspectos, hacen parte de tal memoria. Indudablemente implica selección y, ante todo, olvidos ${ }^{42}$.

La enseñanza de la Historia Patria tenía por objeto transmitir ideales, relatos de gestas, próceres y patriotismo, apuntaba en dirección a perfilar el ciudadano, pero tutelado por el proyecto civilizador, lo que evidentemente dejaba en la invisibilidad y el olvido a aquellas gentes iletradas y de "todos los colores", que quedaron por fuera de la representación de lo nacional como algo importante a reivindicar.

El debate sobre la enseñanza y el estudio de la Historia es un tema vigente, pues concretamente en Colombia hace 20 años que desapareció como materia del currículo escolar de primaria y bachillerato, en su lugar se creó la materia de Ciencias Sociales. A esta problemática se ha sumado la baja calidad de los textos escolares, lo que ha incidido negativamente en la formación de los educandos, pero sobre todo en la conciencia colectiva de los colombianos, de tal forma que se ha empezado a experimentar una suerte de "amnesia colectiva" en el país. Ante esta situación, prestigiosos historiadores y agentes de la cultura se pronunciaron para intentar modificar esta tendencia. A propósito, sostiene el historiador Fabio Zambrano:

Muchos pueden decir que la gente puede vivir sin saber nada de su pasado, pero creo que para una sociedad es sano saber de dónde viene, dónde está y para dónde quiere ir. Imagínese que alguien empiece a vivir a los 20 años con su memoria en cero, borrada, ¿podría vivir bien y planear su futuro? ${ }^{43}$.

\footnotetext{
ello, explica Knight, el discurso patriótico reivindica la soberanía como el fundamento de la dignidad nacional, que se ve amenazada en el momento en que se produce la violación de su territorio, considerado como un símbolo de la integridad nacional, a la que se debe defender entregando incluso la vida. Por esta razón, el patriotismo se hace mucho más sentido en momentos de guerra y revoluciones de independencia cuando se convoca a la población a la defensa de la Patria, para algunos casos se le da un origen mítico que termina por estar presente en el imaginario de los ciudadanos, a quienes se les transmite un discurso a través de diversas formas educativas que buscan inculcar lealtades nacionales que contribuyan a forjar la Patria.

${ }^{41}$ Ibid.

42 Ibid.

43 La crisis de la Historia, en Semana.com, marzo de 2012, http://m.semana.com//nacion/crisishistoria/174321-3.aspx.
} 
Para muchos académicos, todo lo que se ha escrito en la Nueva Historia, nacida en los años sesenta con la creación de las carreras de Historia, sigue sin llegar a las aulas de las escuelas y colegios del país.

Es indudable que para penetrar en profundidad en esta problemática, se hace necesario realizar una lectura crítica de la forma como estos manuales construyeron un conjunto de contenidos comunes que se impartieron en las instituciones educativas del país y cuya impronta llega incluso hasta nuestros días. El objetivo consiste en establecer la interacción entre educación (Escuela), el proceso de formación del ciudadano y de construcción de la nación colombiana. A diferencia de nuestro país, en el plano internacional muchos gobiernos han invertido grandes recursos para recuperar estos materiales históricos del olvido o de su pérdida definitiva, lo que se debe complementar con la posibilidad de su consulta y uso, mediante la creación de bases de datos, legislación y planes de estudio.

Entre los hallazgos del historiador César Lenis acerca de los manuales escolares de Historia Patria del siglo XIX, se encuentra que la invención del "pasado nacional" habría tenido un costo cultural muy alto, puesto que con él se negaron diversas tradiciones y numerosos actores sociales que participaron en la construcción del proyecto de nación, pero que no fueron reconocidos por esa particular representación. En toda América Latina, durante el siglo XX, mediante las historias patrias y las actividades de los intelectuales de la época se promovieron mitos y se crearon identidades ficticias. Las corrientes intelectuales de Hispanoamérica incidieron en la historiografía colombiana y establecieron formatos narrativos que se caracterizaron por su especial interés en los hechos del pasado y la exaltación de la identidad nacional a partir de convenciones culturales.

En este tenor, la historia patria se configuró como una de las principales modalidades discursivas utilizadas por el ideario nacionalista, con su regreso a los próceres, las principales gestas de la independencia y la construcción del Estado, como características de tal producción, que tuvo como función salvaguardar la supuesta unidad nacional a partir del control del pasado.

Los textos escolares que salieron a la luz pública en la primera mitad del siglo XX, requerían de avales políticos de los gobernantes de turno y vistos buenos religiosos de parte de la jerarquía eclesiástica. Esto último a partir del Concordato suscrito entre el Estado colombiano y la Santa Sede en $1887^{44}$. Los manuales escolares, más que una guía o un lineamiento que daba paso a eventuales modificaciones, cambios

\footnotetext{
${ }^{44}$ GONZÁLEZ, Fernán, "El concordato de 1887. Los antecedentes, las negociaciones y el contenido del Tratado con la Santa Sede", Biblioteca virtual Luis Ángel Arango, Mayo 1993, <http://www.banrepcultural.org/ blaavirtual/revistas/credencial/mayo1993/mayo1.htm>. En el artículo 12, que establece que la educación e instrucción pública en universidades, colegios y escuelas deberá organizarse y dirigirse en conformidad con los dogmas y la moral de la religión católica. En esos centros será obligatoria la enseñanza religiosa y la observancia de las correspondientes prácticas piadosas. En consecuencia, el artículo 3 otorga a los obispos el derecho a inspeccionar y elegir los textos de religión y moral. Además, el gobierno se compromete a impedir que se propaguen ideas contrarias al dogma católico y al respeto debido a la Iglesia en la enseñanza del resto de las asignaturas. Finalmente, el artículo 14 concede a los obispos la potestad de hacer retirar a los maestros la facultad de enseñar religión y moral, si no lo hacen en conformidad con la doctrina ortodoxa.
} 
o interpretaciones en el escenario escolar, constituían una camisa de fuerza que limitaba el libre ejercicio de los maestros en sus cátedras y reducía su función a un adoctrinamiento de los estudiantes y futuros ciudadanos. Los contenidos de los manuales eran considerados como la verdadera historia que se debía enseñar.

Este proceso fue respaldado por la función del maestro, que no se limitó simplemente a la enseñanza de las letras y la aritmética, ya que también se le había encomendado el deber de despertar el espíritu cívico, en los estudiantes, recurriendo al conocimiento de la historia oficial, como lo señala Zapata:

Este joven, que por varios años ha estado dirigiendo Escuelas y Colegios, no ha querido olvidar que es el deber del Maestro, no tanto la cuestión mecánica de enseñar Aritmética y Gramática como el de despertar en el espíritu de los que van a ser ciudadanos de un país, el amor por la patria, la gratitud a los fundadores de la Nación, a los que se sacrificaron por nobles ideales y nos dejaron, tinta en sangre, en la Bandera tricolor, el símbolo de la Libertad y del Derecho que nos dejó el heroico empuje de su brazo ${ }^{45}$.

La historia patria en Latinoamérica se esforzó por convertir la independencia en el logro por excelencia de la colectividad. Esto, con la pretensión clara de consolidar y darle forma al Estado-nación, como el gran sujeto surgido de ese momento heroico. Para algunos, la independencia no fue un punto de llegada sino de partida. El sacrificio de una generación sublime, para legarle a las siguientes generaciones un territorio, una identidad y un Estado.

Los manuales escolares contribuyeron a legitimar el nuevo orden político a través de la transmisión de saberes, ideologías, la modelación del sujeto político o ciudadano, en un sistema homogéneo de prácticas, discursos y creencias. Según la historiadora Patricia Cardona: "Si bien tales textos están fundados sobre un pasado legitimador de identidad, son también ficciones de futuro. Sus letras insinúan la formación del ciudadano ideal" ${ }^{46}$.

Para tal efecto, el papel de la Escuela en el transcurso del siglo XIX y la primera mitad del XX, aparte de contribuir a los procesos de socialización, fue el espacio para generar identidad nacional. Por consiguiente, el sistema educativo debió ser controlado, regulado y vigilado, incluidos los docentes, acciones que se convirtieron en unas de las principales funciones del Estado y sus gobiernos. La Escuela se convirtió en el núcleo, centro y lugar clave para difundir mitos, símbolos e identidades colectivas de la nación, no tanto porque no existieran otros (los partidos políticos, el congreso, las elecciones, el ejército), sino por ser el espacio que permitía también la masificación de las tradiciones inventadas, indispensables para diseñar el futuro ${ }^{47}$.

\footnotetext{
${ }^{45}$ ZAPATA, José, Cartera Patriótica, Medellín, Imprenta Oficial, 1925. p. 8.

${ }^{46}$ CARDONA, Patricia, "La nación de papel: textos escolares, política y educación en el marco de la reforma educativa de 1870", en Co-herencia, enero-julio, 2007, <http://redalyc.uaemex.mx/pdf/774/77440605.pdf.

47 HOBSBAWM, Eric y RANGER, Terence, The Invention of Tradition, www.jstor.org/ stable/10.2307/40340766. La invención de la tradición: "Se refiere al conjunto de prácticas, regidas normalmente por reglas manifiestas o aceptadas tácitamente y de naturaleza ritual o simbólica, que buscan
} 
En este sentido y en medio de la disputa que enfrentaba a conservadores y liberales en cuanto al modelo cultural que serviría de referente para redefinir la nación moderna, conviene subrayar el proyecto de la "Revolución en Marcha", liderado por el liberal Alfonso López Pumarejo, y en particular lo referido a su reforma educativa ${ }^{48}$. Para el período comprendido entre 1910 y 1948, tanto liberales como conservadores hicieron énfasis en la educación como uno de los principales instrumentos del progreso nacional. Comenzaron a preocuparse por la necesidad de desarrollar la infraestructura escolar y crear un sistema educativo realmente nacional, cuestión central que involucraba otros aspectos como la higiene en los espacios educativos y la alfabetización básica o educación elemental en todo el país, todo ello con la pretensión de formar ciudadanos y mano obra para el sector productivo.

Con la llegada de los liberales al Gobierno en 1930, se impulsaron grandes innovaciones en esta materia, como la construcción de la infraestructura escolar, la producción y uso de material didáctico (se dio mucha importancia a la difusión del libro), la capacitación y actualización de los maestros, la difusión de las bibliotecas, los avances en pedagogía y la aplicación de nuevas metodologías de enseñanza. Aquí conviene destacar que ya desde la llegada Julio Carrizosa al Ministerio de Educación de en 1931, durante la administración de Enrique Olaya Herrera (1930-1934), se venían intensificando estos propósitos e iniciativas que se reforzaron con la asesoría y el concurso del reconocido pedagogo Agustín Nieto Caballero.

Igualmente, se buscó transformar y modernizar la oficina ministerial, que no tenía ni la más mínima condición de tal, según lo testimonia la memoria del Ministro de Educación al Congreso:

Es necesario que el país no se siga engañando con una oficina que lleva el nombre de Ministerio de Educación. Lo que principalmente existe es un despacho encargado de suministrar recursos para las leproserías, caridad y beneficencia, y que tiene modestos aportes para la enseñanza ${ }^{49}$.

En la medida en que desde la iniciativa de los gobiernos liberales se pretendió organizar y darle norte a este nuevo campo de acción, la educación se convirtió en un espacio de constante fricción y disputa entre las colectividades políticas. Agregado a ello, la alianza estructural entre el Partido Conservador y el clero organizó el frente de los principales opositores de las reformas liberales. Los argumentos de la oposición fueron del siguiente tenor: que se estaba promoviendo una innecesaria burocracia y que en nombre de la educación del pueblo en realidad lo que había era una pérfida

\footnotetext{
inculcar ciertos valores y normas de comportamiento por medio de la repetición, lo que implica de manera automática una continuidad con el pasado".

${ }^{48}$ URREGO, Miguel Ángel, Intelectuales, Estado y Nación: De la guerra de los Mil Días a la constitución de 1991, Bogotá, Siglo del Hombre Editores, 2002. p. 92. "El hecho más destacado del discurso político, debido a la necesidad de reestructura el régimen electoral fue sustituir el concepto de pueblo por el de ciudadanía. Lo cual incidió enseguida por cambios significativos en las prácticas de los partidos”.

${ }^{49}$ Memoria del Ministro de Educación al Congreso de 1930, Bogotá, Imprenta Nacional, p.v. Datos presupuestales en pp. V-VI. Para la distribución de textos y útiles escolares.
} 
intención que buscaba separar a los fieles de la Iglesia. Según el historiador Renán Silva, el clero y el Partido Conservador "[...] vieron las reformas como un elemento disyuntor del orden social" $"$.

En contraste, el proyecto de instrucción pública propuesto por los conservadores desde comienzos de siglo estaba orientado por los principios de la doctrina católica, tal como quedó establecido en la Ley 39 de 1903 y el Decreto 491 de 1904. En efecto, en dichas normas se restringía y controlaba la labor del maestro, por lo cual se organizó una estricta vigilancia y supervisión de las actividades escolares, pues de lo contrario los esfuerzos serían estériles, tal como lo expresaba dicho Decreto: "Inspección constante, multiplicada y suficientemente dotada de medios de acción para que su influencia se haga sentir en cada momento" ${ }^{51}$. Bajo esta misma directriz, el Decreto 0590 de Junio 16 de 1909 reglamentó sobre los visitadores de Instrucción Pública $^{52}$. También se fijaban las conductas y comportamientos que se esperaban de los maestros, cuya transgresión o violación podía conducir a la suspensión de su cargo, como en estos casos: cuando el Maestro cometa una falta grave contra la Religión, la moral o la decencia pública; cuando estén malversando los útiles de la escuela; cuando se hayan entregado al juego o al uso del licor; y cuando se descubra que padecen enfermedad contagiosa. Esta misma normativa estableció la catequización de los indígenas, sobre todo en cuanto a atender la evangelización e instrucción de las tribus salvajes, de acuerdo con el convenio celebrado con la Santa Sede, proyecto que tenía como finalidad expandir la civilización cristiana. Resulta particularmente interesante el artículo 48 del precitado decreto educativo, que define la educación moral como obra más noble y más importante de la misión del Institutor, a la cual debía consagrarse completamente:

La educación moral es la obra más noble, más importante de la misión del Institutor, el cual debe consagrarse a ella completamente, empleando todos los recursos de su inteligencia y de su corazón, a fin de hacer fácil a sus alumnos la práctica de los deberes para con Dios, para consigo mismo, para con sus padres y sus superiores, para con los semejantes y para con la patria ${ }^{53}$.

Como ya se anotó, estos principios y prácticas educativas se mantuvieron durante la Hegemonía Conservadora, de tal manera que su oposición a las iniciativas reformistas de los liberales fue tanto enconada como de fondo. Sin duda, los fundamentos de la oposición estaban cimentados en las anquilosadas y retrógradas estructuras tradicionalistas del país, que reaccionaron estimuladas por el sectarismo político. En estas condiciones, el clero emprendió una movilización a escala nacional de los padres de familia y las comunidades locales para enfrentar las reformas educativas promovidas por el liberalismo, recurriendo en muchos casos a información falsa y sin ningún soporte en la realidad.

\footnotetext{
${ }^{50}$ SILVA, Renán, República liberal, intelectuales y cultura popular, Medellín, La Carreta, 2005, p. 302.

${ }^{51}$ Diario Oficial No. 12122, 14 de julio de1904, Decreto 491 de 1904.

${ }^{52}$ Decreto 0590 de Junio 16 de 1909.

${ }^{53}$ Diario Oficial No. 12122, 14 de julio de1904, Decreto 491 de 1904.
} 
No obstante, la tensión creciente -abierta o soterrada- y las iniciativas educativas de corte liberal promovieron la difusión del libro y la creación de bibliotecas como una posibilidad para alfabetizar y elevar el nivel cultural de la población. El predominio de los analfabetos en la población colombiana de ese entonces constituía un reto para los dirigentes y sectores dominantes e incluso un reclamo ciudadano que provenía desde los más apartados lugares del país. Así lo constatan diferentes solicitudes de textos escolares hechas por los rectores, directores de Escuela, inspectores educativos y maestros, para la dotación de las instituciones educativas ${ }^{54}$. La iniciativa educativa buscaba realmente, mediante campañas dirigidas al conjunto de la población, promover la lectura y el amor a los libros. Existía una preocupación sincera por alfabetizar a la población, no hay dudas acerca de que el Ministerio de Educación efectivamente destinó recursos importantes, de acuerdo a su presupuesto, para suministrar textos y bibliotecas. Para ese efecto emprendieron "La Campaña de Cultura Aldeana", que consistió en acercar a la población rural del país a los conocimientos propios de la cultura occidental, con la pretensión de elevar el nivel cultural de la población e instaurar una forma de vivir más "civilizada". Este proyecto fue un intento de incorporar nuevos elementos ideológicos en la cultura nacional, de marcar una ruta distinta para la identidad colectiva, al separar los asuntos del Estado de los de la Religión, pero por eso mismo fue interpretado por las fuerzas conservadoras y clericales como un intento de arrebatarle a la moral cristiana su centralidad para los colombianos. Tal como lo analiza el educador Luis Bohórquez Casallas:

Desde 1930 el sistema educativo cambió fundamentalmente. Se introdujeron monopolios estatales en la educación [...] Se retiró a las Comunidades Religiosas de la dirección de los establecimientos oficiales que el gobierno anterior les había confiado, se introdujeron métodos racionalistas en los planteles oficiales, y si bien es cierto que hubo algunas reformas acertadas, como la orientación de los maestros, los cursos de información, creación de Normales regulares y rurales, aumento de presupuesto, incremento del cine educativo, conciertos populares, bibliotecas aldeanas, etc., en todo ello iba impresa la tendencia de alejar la moral cristiana de la educación, lo cual contribuyó a que esas campañas no tuvieran el éxito y las resonancias indispensables para su continuidad ${ }^{55}$.

En este contexto, los libros o textos escolares fueron un vehículo vital en la difusión de las ideas ciudadanas o cívicas que se desplegaron en la escuela primaria. Pese a esto, se presentó una dificultad respecto de garantizar una secuencia lógica entre la producción y distribución de esos materiales, de tal manera que hubo inequidad en las cantidades que se entregaban y tardanza en la entrega del material. Por esta razón se incrementó la impresión masiva de cartillas cívicas que promovían contenidos civilizadores como "[...] los derechos ciudadanos, la protección de los niños y la defensa de la familia"56. De modo similar y citando las palabras de Renán Silva:

\footnotetext{
${ }^{54}$ Véase AGN, Archivo Anexo II, Ministerio de Instrucción Pública. Solicitudes de textos, útiles, enseres, para instrucción pública, ff. 1-204, Fecha 1894-1922.

55 BOHÓRQUEZ CASALLAS, Luis, La evolución educativa en Colombia, Publicaciones cultural colombiana, Bogotá, 1956, p. 456.

${ }^{56}$ Silva, Renán, República Liberal..., Op. Cit., p. 184.
} 
El interés por la escuela primaria y por la difusión en ella de textos que pugnaban entre 'científicos y nacionalistas', al lado de la lucha porque la escuela elemental enseñara al niño los fundamentos de toda educación ciudadana, se consideró que las relaciones entre educación y democracia sostenían los liberales en el gobierno ${ }^{57}$.

La educación desempeñó un papel fundamental en los distintos gobiernos de comienzos del siglo XX y con su protagonismo también se incrementó la producción de manuales escolares, por lo cual su importancia simbólica (entre los ciudadanos, los padres de familia y los grupos de opinión), su centralidad en los procesos educativos y la atención especial del Estado fueron también evidentes. Desde el siglo XIX los textos escolares cobraron importancia, se convirtieron en estrategias eficaces a través de las cuales se pretendía impulsar el proyecto de construcción de la Nación, tal como lo afirma Myriam Báez: "Escribir manuales y compendios históricos representaba la materialización del interés de los gobiernos por asimilar las corrientes de pensamiento educativo, y determinar las estrategias para la conformación ideológica, social, cultural y política de la nación"s8. Pero en el siglo XX se multiplicaron de manera notable.

\section{Consideraciones finales}

Los estudios sobre la construcción del Estado-nación tienen una larga tradición en la historiografía latinoamericana y es evidente que estos en general se caracterizan por privilegiar los aspectos institucionales y macroscópicos del proceso, tarea que ha sido realizada por la historia política. Sin embargo, la complejidad de este proceso en la región -el dilema se puede sintetizar en si formar la nación (identidad) o construir el Estado (institucionalidad política)- y los consiguientes matices y variables que asumió, recientemente han conducido a cambios notables en la perspectiva histórica para abordarlos. La historia política ha derivado en historia social y cultural.

El caso colombiano es especialmente complejo y la posibilidad de su replanteamiento desde un ámbito particular de análisis, la educación, nos interesó de manera especial. La unidad nacional fue un asunto difícil de concretar, el país ingresó al siglo XX en el peor de los escenarios imaginables, en medio de la más devastadora de sus guerras civiles, mutilado su territorio nacional, exacerbadas las pasiones políticas por la acción de las dos colectividades históricas -conservadores y liberales- y aplazados los sueños de progreso y paz. En estas condiciones, que adicionalmente fueron presionadas por un dinámico entorno internacional que exigía adhesiones al modelo cultural e institucional de la modernidad diseñado desde Europa y a su base material capitalista en expansión, se configuró en el país un momento especial para intentar resolver la espinosa cuestión de la identidad nacional. Para el efecto concurrieron varios factores como: un relativo sentido pragmático de concordia a raíz de la evaluación de la situación del país al arribar a su primer centenario de la Independencia, el relato histórico nacionalista inventado en el siglo xix pero que se reactivó en las primeras décadas del XX y la coincidencia de unos y otros en el campo político acerca de la importancia de la educación, la instrucción pública y la escuela

\footnotetext{
${ }^{57}$ Ibid, p. 169.

${ }^{58}$ BÁEZ OSORIO, Miryam, Las Escuelas Normales y el cambio educativo en los Estados Unidos de Colombia en el Periodo Radical, 1870-1886, Tunja, Universidad Pedagógica y Tecnológica de Colombia, 2004.
} 
como el espacio adecuado e idóneo para formar al nuevo ciudadano. La construcción de la nación en Colombia ha sido un proceso complejo entre los legados europeos e hispanoamericanos, durante el cual se condicionaron los caminos o vías para la formación de la identidad nacional como parte del Estado moderno. Con matices, en América Latina predominó el ideal de la homogenización cultural de la población entre el siglo XIX y la primera mitad del XX. Aun así, en este proceso no todos siguieron las mismas vías: por un lado, buscaron integrarlos en una misma cultura política y, por el otro, establecer un sistema común de referentes colectivos.

En estas condiciones, los manuales escolares se convirtieron en vehículos ideológicos y doctrinarios de tales imaginarios nacionalistas, especialmente en el ámbito de la Escuela y la educación, a partir de una historia patria de origen decimonónico, pero que se reinventa a comienzos del siglo XX. Más que insinuar el ideal del ciudadano, los manuales escolares fueron determinantes en la difusión del imaginario nacional y en establecer el perfil del sujeto moderno de representación, bajo un modelo europeizante de "blancura ideológica" y racial, la tutela del dogma católico. En Colombia, durante la primera mitad del siglo XX, este fenómeno presentó en forma adicional una dualidad perversa y sectaria entre la dirigencia conservadora y la Iglesia y la dirigencia liberal con su proyecto de una república laica. Tanto así, que en la República Liberal fue necesario emprender un proceso de modernización del país, que no hizo esperar las múltiples reacciones en los grupos más tradicionalistas.

El problema crucial de la formación de la nación y la cuestión de cómo definir al ciudadano, observado desde la situación educativa y a través del análisis crítico de los manuales escolares de historia, cívica y urbanidad, nos permitirá comprender en mejor forma el trasfondo de estas disputas.

\section{Fuentes}

\section{Fuentes Primarias}

\section{Publicaciones seriadas}

Diario Oficial No. 12122, 14 de julio de 1904, Decreto 491 de 1904.

Diario Oficial No. 14923, 20 de junio de 1913, Decreto 536 de 1913.

Diario Oficial No. 20645, 15 de noviembre de 1927, Ley 56 de 1927.

Diario Oficial No. 2318, 19 de mayo de 1936.

Diario Oficial No. 26851, 22 de octubre de 1948.

\section{Documentación primaria impresa}

BOHÓRQUEZ CASALLAS, Luis Antonio, Civismo: para el quinto grado de primaria, Bogotá, Voluntad, [s.f.] .p.63 
HENAO, Jesús María y ARRUBLA, Gerardo, Historia de Colombia: para la enseñanza secundaria, Bogotá, Escuela tipográfica salesiana, 1911. p. 560.

HERMANOS MARISTAS, Aprendamos nuestra historia, Bogotá, Voluntad, 1945.

HERMANOS MARISTAS, Colombia nuestra patria: historia y geografía $4^{\circ}$. grado primaria, Cali, Norma, [s.f.]. P.184

HERMANOS MARISTAS, Historia de Colombia: enseñanza secundaria y primaria superior, Bogotá, Ed. Lumen Christi, 1940. p. 288.

ZAPATA, José, Cartera patriótica, Medellín, Imprenta Oficial, 1925.p. 402.

\section{Fuentes Secundarias}

\section{Libros}

ALMARIO GARCÍA, Óscar, Los sujetos colectivos en la formación del Estado nacional colombiano, Medellín, Universidad Nacional de Colombia, 2007.

ANDERSON, Benedict, Comunidades imaginadas: reflexiones sobre el origen y la difusión del nacionalismo, México, Fondo de Cultura Económica, 1997.

BACZKO, Bronislaw, Los imaginarios sociales. Memorias y esperanzas colectivas, Buenos Aires, Nueva Visión, 1984.

BÁEZ OSORIO, Miryam, Las Escuelas Normales y el cambio educativo en los Estados Unidos de Colombia en el Periodo Radical, 1870-1886, Tunja, Universidad Pedagógica y Tecnológica de Colombia, 2004.

COLMENARES, Germán, Las convenciones contra la cultura. Ensayo sobre la historiografía hispanoamericana del siglo XIX, Bogotá, Tercer Mundo Editores, 1987.

FLORESCANO, Enrique, Etnia, Estado y Nación. Ensayo sobre las identidades colectivas en México, México, Taurus, 2003.

FONTANA, Joseph, La historia de los hombres, Barcelona, Crítica, 2001.

GAUCHET, Marcel, MANENT, Pierre y RONSAVALLON, Pierre, Nación y modernidad, Buenos Aires, Ediciones Nueva Visión, 1997.

GÓMEZ, Elías, La ciudadanía en el federalismo. El proceso de construcción de ciudadanos en el Estado soberano de Cundinamarca 1863-1878, Bogotá, Editorial Pontificia Universidad Javeriana, 2009.

GUERRA, François-Xavier, Modernidad e Independencias, México: Fondo de Cultura Económica, 1993. 
HERRERA CORTÉS, Martha Cecilia, PINILLA DÍAZ, Alexis Vladimir y SUAZA, Luz Marina, La identidad nacional en los textos escolares de ciencias sociales: Colombia 1900-1950, Bogotá, Universidad Pedagógica Nacional, 2003.

HOBSBAWM, Eric, Naciones y nacionalismo, 1780, 2.ed, Barcelona, Crítica, 1997.

HOBSBAWM, Eric y RANGER, Terence, The Invention of Tradition, New York, Cambridge University Press, 1983.

KÖNIG, Hans, En el camino hacia la Nación: Nacionalismo en el proceso de formación del Estado y de la Nación de la Nueva Granada, 1750 a 1856, Bogotá, Banco de la República, 1994.

KÖNIG, Hans, (comp.), Estado-nación, Comunidad Indígena, Industria: Tres debates al final del milenio, Asociación de Historiadores Latinoamericanistas Europeos, 2000.

ROSANVALLON, Pierre, La consagración del ciudadano: Historia del sufragio universal, México, Instituto Mora, 1999.

SÁBATO, Hilda (Comp.), Ciudadanía política y formación de las naciones: perspectivas históricas de América Latina, México, El Colegio de México, 1999.

SILVA, Renán, República liberal, intelectuales y cultura popular, Medellín, La Carreta, 2005.

SMITH, Anthony, Nacionalismo: teoría, ideología, historia, Alianza Editorial, 2007.

URREGO, Miguel Ángel, Intelectuales, Estado y Nación: De la guerra de los Mil Días a la constitución de 1991, Bogotá, Siglo del Hombre Editores, 2002.

WALLERSTEIN, Immanuel (Coord.), Abrir las ciencias sociales. Informe de la Comisión Gulbenkian para la reestructuración de las ciencias sociales. México: Siglo XXI Editores - Centro de Investigaciones Interdisciplinarias en Ciencias y Humanidades, UNAM, 1999.

\section{Capítulos de libros}

FLORESCANO, Enrique, "Un conflicto de hoy y del futuro: las relaciones entre las Etnias, el Estado y la Nación en México", en LABASTIDA, Julio, DEL CAMPO, Martín y CAMOU, Antonio (Coords.), Globalización y Democracia. México y América Latina, México, Siglo XXI Editores, 2001, pp. 394-405.

GUERRA, Françoise-Xavier, "El soberano y su reino. Reflexiones sobre la génesis del ciudadano en América Latina”, en SABATO, Hilda (Comp.), Ciudadanía política y formación de las naciones. Perspectivas históricas de América latina, México, Fondo de Cultura Económica, 1999, pp. 33-61. 
KNIGHT, Alan, "Pueblo, política y nación, siglos XIX y XX", en URIBE, Víctor Manuel y ORTIZ MESA, Luis Javier (Eds.), Naciones, gentes y territorio, Medellín, Universidad de Antioquia, pp. 370-406.

QUIJADA, Mónica, "El paradigma de la homogeneidad", en Quijada, M., BERNAND, C y SHNEIDER, A, Homogeneidad y nación. Con un estudio de caso: Argentina, siglos XIX y XX, Madrid, CSIC, 2000.

QUIJADA, Mónica, "Los confines del pueblo soberano. Territorio y diversidad en la Argentina del siglo XIX", en COLOM GONZÁLEZ, Francisco (Ed.), Relatos de Nación. La construcción de las identidades nacionales en el mundo hispánico. Madrid / Frankfurt am Mein: Iberoamericana / Vervuert. Vol. II. 2005.

LENIS BALLESTEROS, César, "Memoria, olvido y construcción de identidades: la enseñanza de la historia patria en Colombia 1850-1911", en ALMARIO GARCÍA, Óscar, Grupo Etnohistoria y estudios sobre Américas negras, Publicación en CDROOM, Medellín, Universidad Nacional de Colombia, 2008.

MARSHALL, Thomas Humphrey, "Citizenship and Social Class", en Class, Citizenship, and Social Development, Westport, Connecticut, Greenwood Press, 1964.

SÁNCHEZ, Cecilia, "El surgimiento de los Estados-Nación y las políticas pedagógicas como herramientas de integración social y de control en Iberoamérica en el siglo XIX", en ROIG, Arturo Andrés (Ed.), El pensamiento social y político iberoamericano del siglo XIX, Madrid, Editorial Trotta, 2000, pp. 109- 126.

\section{Artículos}

HERRERA, Martha Cecilia, "El memorial de las identidades: entre héroes y villanos. En la busca de sí y de los demás también", en Revista Folios, Bogotá, Universidad Pedagógica Nacional, Ene-jun 2007. pp. 53-61.

HERRERA, Martha Cecilia, "Perspectiva pedagógicas de los textos escolares de Ciencias Sociales en la primera mitad del siglo XX", en Revista Pedagogía y Saberes, Bogotá, Universidad Pedagógica Nacional, vol. 17, 2002. pp. 5-16.

QUIJADA, Mónica, “¿Qué Nación? Dinámicas y dicotomías de la nación en el imaginario hispanoamericano del siglo XIX", en Cuadernos de Historia Latinoamericana. No. 2. Hamburg. Asociación de Historiadores Latinoamericanistas Europeos, 1994.

\section{Publicaciones en internet}

CARDONA, Patricia, "La Nación de papel: Textos escolares, política y educación en el marco de la reforma educativa de 1870", en Co-herencia, Enero-Julio 2007, <http:// redalyc.uaemex.mx/pdf/774/77440605.pdf. 
GONZÁLEZ, Fernán, "El concordato de 1887. Los antecedentes, las negociaciones y el contenido del Tratado con la Santa Sede", Biblioteca virtual Luis Ángel Arango, Mayo 1993, http://www.banrepcultural.org/blaavirtual/revistas/credencial/mayo1993/ mayo1.hm.

\section{Ponencias}

ALARCÓN MENESES, Luís, "Ciudadanía y nación en los textos escolares colombianos del siglo XIX”, en Independencia y transición a los estados nacionales en los países andinos: Nuevas perspectivas, Memorias del Segundo Módulo Itinerante de la Cátedra de Historia de Iberoamérica, Cartagena de Indias, Agosto 10 a 13 de 2004, Bucaramanga, Universidad Industrial de Santander, 2005.

\section{Otros}

ALMARIO GARCÍA, Óscar, "Presentación”, en Grupo Etnohistoria y estudios sobre Américas negras, Publicado en CDROOM, Medellín, Universidad Nacional de Colombia, 2008. 